\title{
Configurações
}

Revista de sociologia

\section{Imigração e crime violento: um olhar a partir de reclusos condenados}

Immigration and violent crime: an analysis from sentenced prisoners

Immigration et crime violent : un regard sur les détenus condamnés

\section{Maria João Guia and João Pedroso}

\section{revues.org}

Electronic version

URL: http://configuracoes.revues.org/2833

DOI: $10.4000 /$ configuracoes.2833

ISSN: $2182-7419$
Publisher

Centro de Investigação em Ciências

Sociais

Printed version

Date of publication: 18 décembre 2015

Number of pages: $25-40$

ISBN: 1646-5075

ISSN: 1646-5075

Electronic reference

Maria João Guia and João Pedroso, «Imigração e crime violento: um olhar a partir de reclusos condenados », Configurações [Online], 16 | 2015, Online since 29 December 2015, connection on 01 October 2016. URL : http://configuracoes.revues.org/2833; DOI : 10.4000/configuracoes.2833

The text is a facsimile of the print edition. 
Guia, Maria João; Pedroso, João - Imigração e crime violento: um olhar a partir de reclusos condenados. Configurações, vol. 16, 2015, pp. 25-40

\title{
Imigração e crime violento: um olhar a partir de reclusos condenados
}

\author{
MARIA JOÃO GUIA* \\ Universidade de Coimbra \\ JOÃO PEDROSO** \\ Universidade de Coimbra
}

\section{Resumo}

Os estudos sobre imigração e crime violento têm vindo a demonstrar, nos últimos anos, a inexistência de uma correlação: na verdade os estudos norte-americanos mais atuais revelam que, nas áreas onde entram mais migrantes, o crime violento tem tido tendência a diminuir. Tal é explicado pela teoria da seletividade e pela busca dos migrantes por melhores condições de vida, evitando atrair visibilidade sobre si. No estudo levado a cabo sobre reclusos condenados por crimes que considerámos violentos, verificámos que apenas nos roubos os migrantes se destacam na curva de aumento de condenações, não sendo, no entanto, os resultados estatisticamente significativos.

Palavras-chave: crime violento; imigração; reclusos; condenações.

\begin{abstract}
Immigration and violent crime: an analysis from sentenced prisoners

Research on immigration and violent crime has been showing, in recent years, the inexistence of a correlation: in fact, the most recent North-American studies reveal that in areas where immigrants tend to settle the most, violent crime has been decreasing. This is explained by the selectivity theory and the migrants' search for better conditions of living, avoiding attracting attention to themselves. In the research made on inmates convicted for crimes that we considered violent, we concluded that only in robbery crimes migrants stand out in the rise of convictions. Nevertheless, these results are not statistically significant.
\end{abstract}

Keywords: violent crime; immigration; inmates; convictions.

\footnotetext{
* Doutorada, Universidade de Coimbra. E-mail: mariaguia@ces.uc.pt.

** Doutorado, Professor na Faculdade de Economia da Universidade de Coimbra e Investigador do Centro de Estudos Sociais da Universidade de Coimbra. E-mail: jpedroso@fe.uc.pt.
} 


\section{Résumé \\ Immigration et crime violent : un regard sur les détenus condamnés}

Les études sur l'immigration et le crime violent n'ont jusqu'à présent démontré aucune corrélation entre ces deux concepts : en effet, les plus récentes études nord-américaines révèlent que les régions qui reçoivent le plus de migrants sont celles qui présentent une baisse du crime violent. Cela s'explique à travers la théorie de la sélectivité et de la recherche de meilleures conditions de vie de la part des migrants, qui évitent ainsi d'attirer l'attention sur eux. Dans l'étude qui a porté sur les détenus condamnés pour crimes considérés violents, nous avons constaté que, sur la courbe des condamnations, les migrants ne se démarquent que pour les vols. Cependant, les résultats ne sont statistiquement significatifs.

Mots-clés: crime violent ; immigration ; détenus ; condamnations.

\section{Introdução}

A globalização, presente em quase todas as atividades e áreas relacionadas com o ser humano, veio a revelar-se crucial no que respeita aos movimentos migratórios. A globalização jurídica, plasmada no direito da "gente que atravessa fronteiras" (Sousa Santos, 2009: 358-359), favoreceu a facilidade de movimentação de pessoas, mas também aspetos perversos inerentes aos grandes movimentos de populações recebidas pelos autóctones com bastante reserva.

"Nas nossas sociedades de bem-estar social intensificam-se reacções etnocêntricas da população local contra tudo o que é estrangeiro - ódio e violência contra estrangeiros, contra adeptos de outros credos ou pessoas de cor, mas também contra grupos marginais e contra os portadores de deficiências" (Habermas, 2001: 92 apud Bittar, 2006).

A questão da eventual relação entre imigração e criminalidade violenta tem vindo a ser analisada internacionalmente por vários autores e há já uns anos em Portugal. Formou-se um espaço crescente de análise, nomeadamente quando a questão que se nos colocou foi a de saber se esta seria a criminalidade que mais perturbava a sensação de bem-estar da população autóctone. Haveria razões para alarme social no que respeita à entrada de um maior número de imigrantes e de um suposto aumento da prática de crimes violentos por parte dos mesmos? Comparativamente a resultados encontrados nos Estados Unidos (Rumbaut e Ewing, 2007; Sampson, 2008; Stowell, 2007; Wadsworth, 2010), país considerado mais intolerante nos últimos anos no que respeita a este assunto, haveria diferenças assinaláveis? Estaria Portugal a perder a sua tradicional tolerância quanto ao acolhimento de indivíduos não nacionais ${ }^{1}$ ?

1 Estas foram algumas das questões levantadas e respondidas em Guia (2015) e que aqui não poderão,
pela limitação de espaço, ser todas desenvolvidas. Sendo, no entanto, algumas das que nortearam a 
Algumas destas questões começaram a tomar forma mais definida à medida que tivemos oportunidade de ir aprofundando esta temática, nomeadamente através da leitura de diversos autores.

\section{Metodologia}

Neste breve artigo, fazemos a revisão da literatura internacional mais relevante neste campo.

Traçámos um conceito de criminalidade violenta que abrangesse a perspetiva internacional, tendo para isso consultado fontes do Eurostat e do FBI, entre outras. Este artigo resultou de um debate entre os autores com base nos resultados obtidos a partir da investigação da tese de doutoramento de Guia (2015). Apresentamos aqui alguns excertos relevantes para o argumento, nomeadamente dados quantitativos e qualitativos recolhidos e analisados neste âmbito, procurando uma análise poliédrica ${ }^{2}$ que abrangesse várias vertentes da mesma questão.

Este estudo centrou-se no seguinte objetivo geral: identificar eventuais relações ${ }^{3}$ - significativas ou não - entre a condenação de crimes violentos e determinados grupos de migrantes (que não serão aqui especificados - imigrantes, circulantes de países terceiros, euromigrantes e visitantes da $\mathrm{UE}^{4}$ ), fazendo menção, em casos pontuais, das nacionalidades respetivas.

Nesse contexto, analisámos o crime violento ${ }^{5}$ em Portugal, estabelecendo os crimes de homicídio, roubo, ofensas à integridade física e violação como objeto de investigação, procurando, através das variáveis dos reclusos condenados em Portugal ${ }^{6}$ entre os anos de 2002 e 2011, encontrar dados que evidenciassem a intervenção dos indivíduos não nacionais na prática destes quatro crimes. O estudo efetuado não comprovou nenhuma relação entre imigração e crime violento, à exceção do crime de roubo, em que existe uma crescente sobrerrepresentação de condenados não nacionais.

presente investigação e ainda que, no contexto do presente artigo, algo ambiciosas, deixamo-las para que o leitor percecione o debate desenvolvido, apresentado e defendido publicamente.

${ }^{2}$ Referimos esta análise como 'poliédrica' porque revestida de diversas faces de um mesmo todo, intrinsecamente relacionadas e inseparáveis, qual um verdadeiro 'Janus' de abordagem: duas caras (neste caso várias), um só corpo.

3 Procurámos diferenciar relações e correlações pela força e vínculo de cada designação.

4 Para informação completa sobre estes grupos de migrantes, vide Guia, 2014: 143; 2015:8.

5 Tivemos, por isso, de construir um conceito de criminalidade violenta, internacionalmente aceite, deixando conscientemente de lado uma série de crimes que poderiam ser considerados violentos, mas que não nos permitiriam a análise empírica do que aqui apresentamos.

${ }^{6}$ Abordamos neste artigo apenas o cume da pirâmide da justiça criminal, não seguindo o processo de seleção da criminalidade (Guia, 2015: 261), estando conscientes de que a sua base assenta em cifras negras (segundo Almeida e Alão, 1995 apud Guia, 2015: 253 apenas chega ao conhecimento das polícias cerca de $30 \%$ dos crimes efetivamente cometidos) e de que se vai perdendo informação à medida que se progride nos sucessivos patamares da investigação criminal/justiça (denúncias, registos de crimes, investigação, acusação, condenação e reclusão). Consideramos, no entanto, ser apenas possível usar estes dados por estarem disponíveis e serem comparáveis entre nacionais e não nacionais. 


\section{0 conceito de criminalidade violenta}

A violência é apontada como uma das causas principais da morte de mais de um milhão de seres humanos por ano em todo o mundo, com idades entre os 15 e os 44 anos (OMS, 2002: 3). Estabelecer um conceito de violência não se restringe à análise do ato físico de emprego de força, uma vez que um facto violento também se pode exercer através das palavras; deve ter-se sobretudo em conta o contexto da sociedade em que o indivíduo que o comete se insere. O termo violência foi apresentada pela Organização Mundial da Saúde (OMS, 2002) como o

"uso intencional da força ou poder em uma forma de ameaça ou efetivamente, contra si mesmo, outra pessoa ou grupo ou comunidade, que ocasiona ou tem grandes probabilidades de ocasionar lesão, morte, dano psíquico, alterações do desenvolvimento ou privações.” (OMS, 2002: 5)

O conceito de criminalidade violenta é alvo de debate, podendo diferir de sociedade para sociedade e dependendo das épocas. Estudos recentes apontam para a investigação levada a cabo no que concerne à intervenção de fatores biológicos e individuais como indicadores da "predisposição para a agressão", ainda que se conjuguem com fatores externos (Dahlberg e Krug, 2007: 1164).

A criminalidade violenta é definida no Código do Processo Penal, aprovado pelo Decreto-Lei n. ${ }^{\circ} 78 / 87$, de 17 de fevereiro, republicado pela Lei n. ${ }^{\circ}$ 48/2007, de 29 de agosto, (art. 1. ${ }^{\circ}$, alínea j), como "as condutas que dolosamente se dirigirem contra a vida, a integridade física ou a liberdade das pessoas e forem puníveis com pena de prisão de máximo igual ou superior a 5 anos". A Lei n. ${ }^{\circ}$ 26/2010, de 30 de agosto, vem depois juntar a este conceito "as condutas que dolosamente se dirigirem contra (...) a liberdade pessoal, a liberdade e autodeterminação sexual ou a autoridade pública”. A criminalidade especialmente violenta é definida, na alínea seguinte do mesmo diploma, como "as condutas previstas na alínea anterior puníveis com pena de prisão de máximo igual ou superior a 8 anos", tendo-se mantido com o mesmo texto, na sequência das alterações posteriores. A criminalidade altamente organizada era referida na Lei n. ${ }^{\circ}$ 48/2007, de 29 de agosto, na alínea m), como "as condutas que integrarem crimes de associação criminosa, tráfico de pessoas, tráfico de armas, tráfico de estupefacientes ou de substâncias psicotrópicas, corrupção, tráfico de influências ou branqueamento". As alterações introduzidas com a Lei n. ${ }^{\circ}$ 26/2010, de 30 de agosto, acrescentam-lhe também a prática do crime de "participação económica em negócio ou branqueamento".

Apesar de o Código do Processo Penal (e a legislação avulsa) usar de um critério baseado na duração da pena (igual ou superior a 5 anos de pena de

\footnotetext{
7 “... tais fatores interagem com fatores familiares, comunitários, culturais ou outros fatores externos, criando situações em que a violência pode ocorrer” (Dahlberg e Krug, 2007: 1164).
} 
prisão), e atendendo a que estas normas abrangem uma pluralidade de crimes que não permitiria trabalhar as questões relacionadas com a imigração, tivemos de construir um conceito de criminalidade violenta que permitisse estudar a intervenção dos cidadãos não nacionais residentes e não residentes em Portugal. Assim, o conceito aqui apresentado foi construído, não com base na referência à duração da pena, mas atendendo aos valores que as sequelas decorrentes constituem para o ser humano (atentando contra a vida humana, integridade física e liberdade sexual). Tentámos então construir um conceito de violência que não oferecesse dúvidas, tendo sido forçados a limitar a nossa escolha por questões práticas: tivemos em atenção que iríamos usar dados estatísticos relativos a reclusos condenados constantes dos dados públicos da ex-Direção-Geral dos Serviços Prisionais.

Criminalidade violenta é, por isso, e para efeito desta investigação, o conjunto de condutas dolosas que integram os requisitos destes quatro "tipos legais” de crimes: homicídio, roubo, ofensas à integridade física e violação. São condutas que se dirigem e atentam contra a vida (homicídio), a integridade física humana (ofensa à integridade física e roubo) e a liberdade de autodeterminação sexual (violação). Este conceito que apresentamos é construído, assim, com base no estatuído no Código do Processo Penal, mas também com base na natureza substantiva dos factos que se revestem de natureza violenta.

Devemos ainda salientar que os crimes considerados no presente estudo como violentos coincidem, na sua origem, com aqueles que são especificados nas estatísticas do Eurostat como violentos ("violência contra as pessoas como ofensas à integridade física -, roubo - roubo pela força ou por ameaça de uso de força - e ofensas sexuais - incluindo violação e abuso sexual"). Esta escolha vai ainda ao encontro dos crimes escolhidos pelo FBI - homicídio, roubo, violação e ofensas à integridade física -, os mesmos referidos por investigadores que anteriormente estudaram esta temática (Almeida e Alão, 1995: 155; Albrecht, 1997; Seabra e Santos, 2006).

\section{Imigração e crime violento: abordagens plurais internacionais}

Após uma leitura atenta dos estudos internacionais e nacionais, e refletindo sobre a relação entre imigração e criminalidade violenta, verificámos que os mais atuais, desenvolvidos nos EUA, defendem a inexistência de correlação positiva entre estas duas realidades, verificando-se, pelo contrário, que a imigração tem vindo a favorecer a descida da criminalidade violenta (Rumbaut e Ewing, 2007; Stowell, 2007; Sampson, 2008; Wadsworth, 2010).

Não só estes autores, como outros académicos (Martinez, 2002, 2006; Ellis et al., 2009; Martinez et al., 2008; Lee e Martinez, 2009; Tonry, 2014 apud Guia, 2015) defendem, através da teoria da seletividade, entre outras causas e fatores, que a imigração contribui para a diminuição do registo dos crimes violentos, 
ainda que estudos oficiais ${ }^{8}$ apresentem resultados contraditórios; os mais recentes apontam para as conclusões já referidas da ausência de aumento do crime (sobretudo violento) ligada ao aumento do número de imigrantes (Immigration Policy Centre - American Immigration Council, 2007, 2013 apud Guia, 2015).

Alguns estudos relacionam a pobreza e a imigração com a criminalidade (Tonry, 1995 apud Guia), com base na existência de supostos conflitos culturais (Sellin, 1938 apud Guia; Sutherland, 1947 apud Guia, 2015) e da desorganização social (Shaw e McKay, 1942 apud Guia, 2015) resultante de privações económicas, da desigualdade no acesso ao mercado de trabalho e à justiça e de xenofobia (Baganha, 1996; Bianchi et al., 2008a, 2008b; Cunha 2008; Seabra e Santos, 2005, 2006; Tonry, 1995, 2004; Tournier, 1996; Wacquant, 1998, 1999 apud Guia, 2015).

Refira-se ainda que alguns investigadores norte-americanos (Brimelow, 1996; Lamm e Imhoff, 1985 apud Guia, 2015) têm referido que a crença de que os imigrantes são diretamente responsáveis pelo aumento das taxas de criminalidade tem sido muito bem aproveitada pelos movimentos nacionalistas, partidos políticos e até por alguns académicos que a utilizam para direcionar determinados pontos de vista e explicar "a ansiedade social e queixas vitriólicas sobre o reino de terror da imigração" (Sampson, 2008: 29). Algumas teorias do crime, sobretudo a da "desorganização social" da Escola de Chicago, apresentam várias razões para explicar de que a forma a imigração e o crime violento estão relacionados por causalidade (Stowell, 2007). Sobre a quintuplicação do número de reclusos nos EUA desde meados dos anos 70, sem que as taxas de crime tivessem registado aumentos significativos e havendo inclusivamente uma descida marcante desde 1993, Wacquant afirma que se verificou uma severidade progressiva que se estendeu a todo o tipo de transgressões, incluindo o crime violento, "com um zelo inversamente proporcional à gravidade da infração" (Wacquant, 2008: 55 apud Gomes, 2014: 53). Para corroborar esta constatação, e segundo um estudo levado a cabo por Irwin e Austin (1997: 32-57) sobre 154 reclusos escolhidos aleatoriamente em três estados norte-americanos (Washington, Nevada e Illinois), mais de metade daqueles tinha sido acusada por crimes menores que não envolviam qualquer tipo de violência, o que permitiu a estes autores constatar que "a maior parte dos reclusos são criminosos de ocasião" (por oposição aos "criminosos profissionais") que não estariam presos se a população conhecesse o seu perfil e as circunstâncias que os levaram a quebrar a lei (Wacquant, 2008: 58 apud Gomes, 2014: 53).

Estudando os reclusos no ano de 1992, ano do pico no número de reclusos nas prisões nos EUA, Wacquant afirma que o indivíduo típico em reclusão,

\footnotetext{
${ }^{8}$ Relatórios estatísticos do Estado, sem que uma análise académica ampla e correlacionando outros fatores que não apenas os estatísticos seja tida em conta. Encontrámos disparidades sobretudo no caso norte-americano, ainda que os dados sejam cuidadosamente apresentados (ICE, 2008; NGIC, 2011; GAO, 2011; United States Department of Justice, 2013).
} 
além de ultrapassar os $50 \%$ de origem afro-americana (cerca de $54 \%$ do total dos reclusos), se encontrava ali por "um crime não violento, em mais de sete casos em cada dez" (Wacquant, 2008: 56). Este autor apresenta como causas explicativas das altas taxas de reclusão a criminalização da pobreza, a falta de proteção social e a estigmatização do gueto, acrescentando que os negros que habitam nos guetos urbanos são os principais agressores no crime violento mas também as principais vítimas dos mesmos (Wacquant, 2008: 68).

Segundo Gurr ${ }^{9}$ (1989), "as três grandes ondas de criminalidade nos Estados Unidos podem ser relacionadas com a imigração". No entanto, este autor defende que, no que concerne à criminalidade violenta, a relação já aparenta ser inversa. Ou seja, a criminalidade violenta apresenta taxas inversamente mais baixas nos locais de maior concentração de imigrantes recém-chegados aos EUA (Sampson, 2008; Stowell, 2007; Gurr, 1989 apud Guia, 2015; Sampson e Bean, 2006 apud Guia, 2015). Um dos fatores explicativos apresentados para esta conclusão prende-se com a diversidade de origens e características dos imigrantes recém-chegados. A teoria da seletividade apresenta aqui várias razões para explicar este fenómeno (Model, 1995; Hagan e Palloni, 1999; Mujahid et al., 2008 apud Guia, 2015). Os imigrantes recém-chegados aos EUA são caracterizados como "mais ambiciosos, talentosos e diligentes" (Model, 1995 apud Guia, 2015), podendo beneficiar, ao mesmo tempo, de redes sociais de apoio que lhes facilitam o acesso à informação e à deslocação, o que facilita o seu processo de adaptação (Palloni e Morenoff, 2001; Hagan et al., 2008 apud Guia, 2015). Esta teoria revela que os imigrantes que decidem viajar para os Estados Unidos o fazem para melhorar as suas expectativas de vida, o que, segundo Tonry (1997), contribui para a menor probabilidade de estes entrarem em práticas criminais porque se encontram a trabalhar afincadamente, esperando um futuro com melhores oportunidades.

Em Portugal, a investigação tem-se centrado nos problemas económicos, na exclusão, na xenofobia e na insegurança, áreas eleitas dos meios de comunicação, focando-se os estudos maioritariamente sobre as populações prisionais (Malheiros e Esteves, 2001; Rocha, 2001; Cunha, 2008; Fonseca, 2010 apud Guia, 2015), na discriminação negativa de imigrantes relativa a acusações, condenações e prisões preventivas (Baganha, 1996; Seabra e Santos, 2005, 2006), bem como na relação entre imigração e crime (Seabra e Santos 2005, 2006; Guia, 2008, 2010a, 2010b, 2010c, 2014; Peixoto, 2008 apud Guia, 2015). Malheiros coordenou um estudo publicado em 2007, intitulado "Espaços e expressões de conflito e tensão entre autóctones. Minorias migrantes e não migrantes na área metropolitana de Lisboa", apresentando razões maioritariamente voltadas para os bairros de Lisboa, as carências económicas

\footnotetext{
9 A clássica escola de Chicago menciona que a imigração tem sido tradicionalmente encarada como fator de aumento do crime.
} 
e de privação social, os grupos de rua (incluindo os violentos) e a socialização que os jovens oriundos de etnias e outras nacionalidades fazem neste meio, o conflito, a violência e o início do pequeno crime cometido nestas zonas como fatores visíveis e seletivos sobre estas populações. As reflexões sobre a violência grupal, pequena criminalidade, criminalidade organizada, perigosa e potencialmente violenta assumem particular relevância, associadas ao tráfico de droga que ocorre em alguns daqueles bairros periféricos transformados em "guetos de exclusão". Salienta-se neste estudo a chamada de atenção para "a falta de acompanhamento e de apresentação de alternativas para os jovens [que] acabará, inevitavelmente, por conduzir alguns destes à criminalidade adulta, necessariamente mais grave e violenta" (Malheiros, 2007: 258).

Os dados estatísticos nacionais atribuem uma percentagem inferior de crimes violentos aos reclusos não nacionais, mas uma maior taxa de incidência dentro desse grupo (Guia, 2010: 61). Também em Portugal, apesar das discrepâncias e da falta de uniformização entre as variáveis envolvidas, não é possível até ao momento estabelecer uma correlação entre imigração e criminalidade violenta. Os dados nacionais disponibilizados sugerem a existência de uma percentagem inferior de crimes violentos entre os reclusos não nacionais, mas uma taxa de incidência superior. Verifica-se ainda uma sobrerrepresentação de reclusos não nacionais nas prisões e uma quase convergência de opiniões no que concerne a uma maior vulnerabilidade, desigualdade, pobreza, desestruturação familiar e social, carência económica, desigualdade no acesso à justiça e discriminação subtil por parte do sistema judiciário relativamente aos agressores não nacionais.

O presente artigo tem, por isso, como enquadramento as teorias mais recentes sobre imigração e criminalidade, as quais se centram numa relação sem causa-efeito, podendo existir, eventualmente, uma relação positiva entre o aumento do número de imigrantes e a descida do número de registos de crimes violentos.

\section{Abordagem empírica aos dados colhidos sobre imigração e crime violento: alterações na geografia da imigração}

Portugal registou, desde meados do século XX até ao início do século XXI, profundas mutações nos fluxos migratórios, quer a nível quantitativo, quer a nível qualitativo.

Podemos inferir a existência de, pelo menos, quatro momentos distintos na imigração em Portugal: o primeiro, de $1981^{10}$ a $1992^{11}$; o segundo, de 1992

\footnotetext{
${ }^{10}$ Apesar de o marco poder fixar-se pelo ano de 1975.

11 Para regularizar a situação dos imigrantes indocumentados, nos anos 90 do século XX, mais precisamente em 1992-93, efetuaram-se campanhas de regularização extraordinárias.
} 
Gráfico 1.

Número de cidadãos portugueses e de indivíduos não nacionais residentes em Portugal (1981 a 2012)

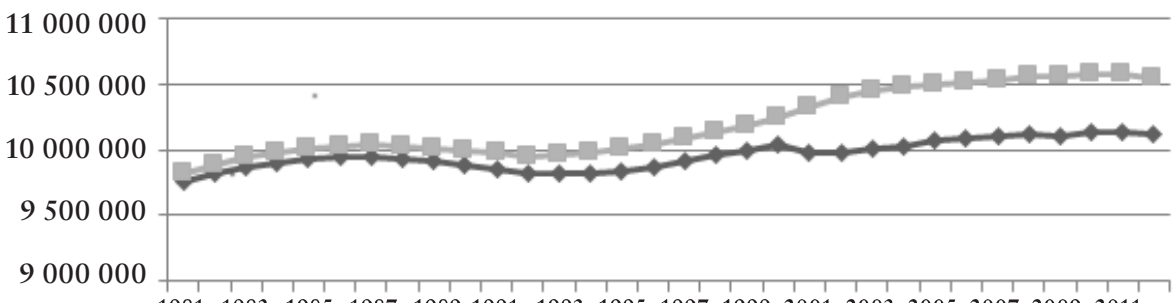

$1981198319851987.19891991199319951997199920012003 \quad 2005 \quad 2007,2009,2011$

$\multimap$ Só portugueses $-\longrightarrow$ Portugueses e não nacionais

Fonte: Eurostat e SEF.

a 2004'2; o terceiro, de 2004 a 2009; e o quarto de 2010 até ao presente. Estes movimentos foram acompanhados de alterações legislativas que foram sendo feitas no que respeita à gestão da imigração, designadamente, das regularizações extraordinárias.

De acordo com João Peixoto (2004), os regimes migratórios caracterizam-se por transições suaves e lógicas (Zelinsky, 1971 apud Peixoto, 2004) entre fases dominadas pela imigração e fases dominadas pela emigração, transições que respondem aos processos económicos em marcha. Portugal parece destacar-se, entre os Estados-membros da UE, como um país onde as saídas não diminuíram com a adesão ao espaço único, como aconteceu com outros países menos desenvolvidos (Peixoto, 2004: 3).

Em 2011 (segundo o Censos de 2011 apud Guia, 2015), a população portuguesa contabilizava 10561614 habitantes, tendo aumentado 2\% relativamente à década anterior. As razões para tal prendem-se com o envelhecimento da população $0^{13}$, o prolongamento da esperança média de vida ( $19 \%$ da população têm 65 ou mais anos), bem como a entrada de cerca de 200000 imigrantes entre 2001 e 2004.

No que respeita às principais nacionalidades de indivíduos não nacionais (oriundos da UE e de países terceiros), constata-se que as nacionalidades

12 Em 1996, foram concedidas autorizações de residência a cerca de 40000 cidadãos. Já no início do século XXI e para responder às fortes pressões dos lobbies da construção civil, obras públicas, da indústria do turismo, entre outras, promulgou-se o Decreto-Lei n. ${ }^{\circ} 4 / 2001$, de 10 de janeiro, ao abrigo do qual se regularizou a permanência em território nacional de 184000 trabalhadores imigrantes com contrato de trabalho, previamente registado no Ministério do Trabalho, entre 2001 e 2003 (Baganha, 2005 apud Guia, 2015).

13 Há 40 anos, a população portuguesa tinha mais jovens do que idosos. 
de residentes mais representadas em Portugal têm sido as relativas a Países Africanos de Língua Oficial Portuguesa (PALOP), com um maior número de residentes oriundos de Cabo Verde ${ }^{14}$. O Brasil ${ }^{15}$ tem sido um país com grande número de indivíduos a fixarem a sua vida em Portugal, sendo em 2011 a maior comunidade de residentes ( $\mathrm{n}=119$ 363). A Ucrânia e a Roménia, países com os quais Portugal não manteve relações de tradição histórico-cultural (como com os países da CPLP), têm visto crescer as suas comunidades de residentes em Portugal, sendo os indivíduos romenos em 2011 a quarta comunidade de indivíduos não nacionais mais numerosa em Portugal.

\section{Criminalidade violenta em Portugal, no contexto da EU}

\subsection{Descida do registo da criminalidade violenta em Portugal}

Segundo o Eurostat ${ }^{16}$, em 2010, Portugal apresentava 24251 registos de crimes violentos, inserindo-se no contexto do número médio de crimes violentos registados nos países europeus ( $\mathrm{n}=86388,66 \mathrm{em} 2010)$. O valor mais alto devia-se aos registos no Reino Unido ( $\mathrm{n}=1007$ 579) e o mais baixo aos do Montenegro $(\mathrm{n}=352)$, segundo a mesma fonte.

$\mathrm{Na}$ generalidade, os relatórios de 2012 e 2013 publicados pelo Eurostat registam descidas na criminalidade violenta ${ }^{17}$ nos vários Estados-membros $\mathrm{e}$ uma descida geral de $7 \%{ }^{18}$ de 2006 para 2009 nos registos efetuados pelos OPC. Segundo Clarke (2013: 2), esta descida deve-se em grande parte à diminuição dos registos em Inglaterra e no País de Gales, onde se registou uma diminuição de 146000 crimes violentos $^{19}$ entre 2007 e 2010.

Analisando agora o que foi possível apurar da "criminalidade estatística" violenta tendo em conta a população de cada Estado, verificamos que a taxa de crimes registados pelas autoridades policiais em Portugal se aproxima da média (média n=395 por 100000 habitantes na UE27), situando-se em $14 .^{\circ}$

${ }_{14}$ Cabo-verdianos residentes em Portugal em 2002, n=52 377; em 2005, n=61 515; em 2008, n=51 353; em 2011, n=43 979;

15 Brasileiros residentes em Portugal em 2002, n=24 864; em 2005, n=49 678; em 2008, n=106 961 ; em 2011, n=119 363 .

16 Apesar de a fonte mencionada ser o Eurostat, esta reflexão deveu-se à consulta da página http:// www.europeinnumbers.com/indicator_static_graph.php?indicatorId=violent_crimes\&multiplier=1 \&iround=0\&graphTitle=\&top_ten=all\&top_ten_sel=all\&regions $=1$ w $\&$ year $=2010$, acedida a 10 de março de 2014

${ }_{17}$ Os crimes mencionados no relatório de 2012 que constam como criminalidade violenta incluem violência contra as pessoas (como crimes de ofensas), roubo (ou seja, furto com violência) e ofensas sexuais. Salvaguarda-se a nota de que nem todos os Estados-membros usam parâmetros semelhantes para a designação de crimes violentos.

18 O relatório de Clarke (2013: 2), também publicado pelo Eurostat, refere-se a uma descida de 6\% entre os anos de 2007 e 2010.

19 Este relatório já apresenta uma especificação mais objetiva de crimes violentos, referindo-se expressamente aos crimes de violência contra as pessoas (ofensas), roubos por meio de violência ou ameaça de uso de força e ofensas sexuais incluindo violação e agressões sexuais. 
Gráfico 2.

Média de crimes violentos registados pelos OPC em 2010, por 100000 habitantes - UE27

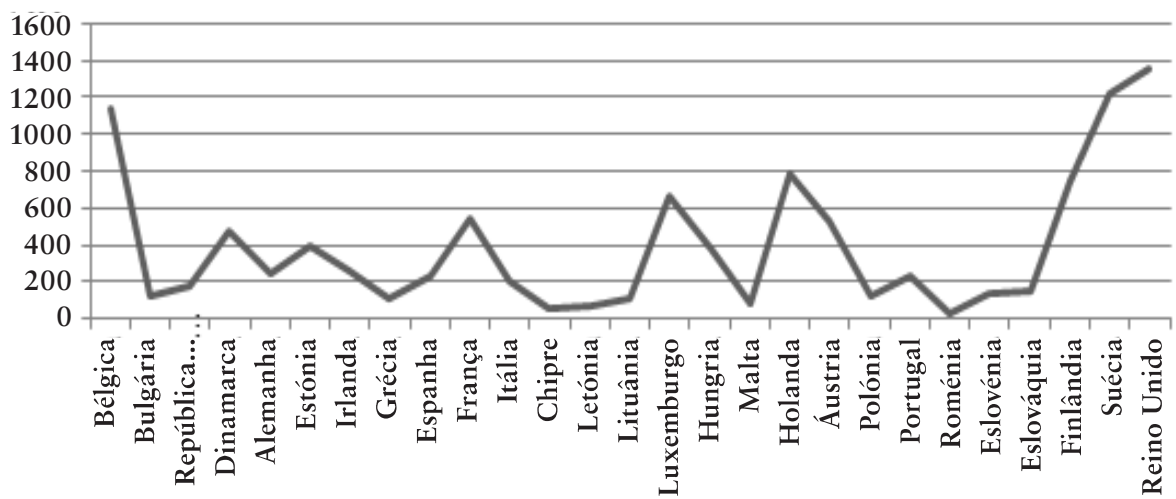

Fonte: Eurostat.

lugar no cômputo dos 27 Estados da UE (taxa de 229 registos de crimes violentos por 100000 habitantes). A taxa mais alta é a da Suécia ( $\mathrm{n}=1612$ crimes violentos registados por 100000 habitantes) e a mais baixa é a da Roménia (com uma taxa de 26 registos de crimes violentos, por 100000 habitantes), conforme se observa no Gráfico 2.

Usando o parâmetro dos países com médias de crimes violentos acima dos 400 por 100000 habitantes, constata-se que são os países do Centro-Norte da Europa que apresentam maior número de registos de crimes violentos: Bélgica, Dinamarca, França, Luxemburgo, Holanda, Áustria, Finlândia, Suécia e Reino Unido. Abaixo desse valor, estão os países do Sul, em crise económico-social, e os de Leste: Bulgária, República Checa, Alemanha (exceção), Irlanda, Grécia, Espanha, Itália, Chipre, Letónia, Lituânia, Hungria, Malta, Polónia, Portugal, Roménia, Eslovénia e Eslováquia.

\subsection{0 aumento das condenações: especificidades não nacionais/portugueses}

Quanto às oscilações nos aumentos e descidas dos crimes, agregados em "tipos de crimes" por bem jurídico protegido, podemos inferir, através da análise do número absoluto de condenações por 100000 habitantes, em 2002, 2005, 2008 e 2011 (vide Gráfico 3), que, de 2008 para 2011, houve um aumento no número de condenações em todos os "grupos de crimes" ${ }^{20}$, mesmo nos relativos

\footnotetext{
${ }^{20}$ Houve um aumento numérico nas condenações de reclusos não nacionais: em 2002, n= 1209 condenados; 2005, $\mathrm{n}=1644 ; 2008, \mathrm{n}=1525$ e $2011, \mathrm{n}=1980$.
} 
Gráfico 3.

Reclusos condenados por tipos de crime (2002, 2005, 2008 e 2011), por 100000 habitantes

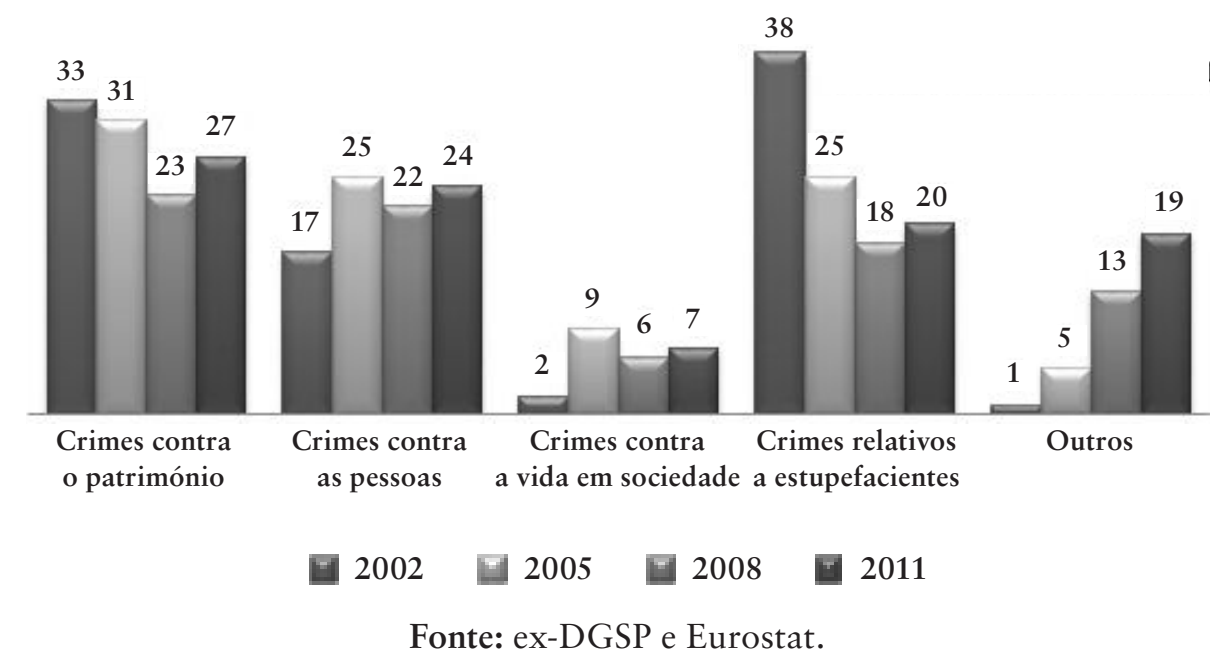

a estupefacientes. Tal verifica-se, apesar da descida progressiva de condenações que se verificou de 2002 para 2008 nos crimes contra o património e crimes relativos a estupefacientes. Os crimes contra as pessoas apresentam oscilações de 2002 para 2008, e os crimes incluídos na categoria "outros" ${ }^{21}$ mostram um claro aumento progressivo de 2002 para 2011.

Observando agora os dados de 2011, verificamos que os reclusos portugueses se encontram maioritariamente representados nas condenações por crimes contra o património ( $29,4 \%$ da totalidade), seguidas das condenações por crimes contra as pessoas $(25,6 \%)$, crimes relativos a estupefacientes $(16,4 \%)$, crimes incluídos na categoria "Outros" $(21,2 \%)$ e, por fim, crimes contra a vida em sociedade $(7,5 \%)$.

As condenações dos indivíduos não nacionais no mesmo ano têm uma distribuição diferente: a maior fatia das condenações, e a única que ultrapassa a dos reclusos portugueses condenados, corresponde a crimes relacionados com estupefacientes $(39,9 \%)$, seguindo-se depois, e sempre em percentagem inferior à dos portugueses, de crimes contra o património $(22,6 \%)$, crimes contra as pessoas $(20,8 \%)$, crimes incluídos na categoria "Outros" $(9,8 \%)$ e crimes contra a vida em sociedade $(6,9 \%)$.

${ }^{21}$ Esta categoria integra todos os outros crimes que não são englobados nas categorias anteriores, previstos em legislação avulsa, sendo apenas individualizado o crime de "cheques sem provisão". Para além desta menção, em 2011 é referido também que dos 1962 crimes incluídos nesta categoria "outros", 965 se reportam a crimes rodoviários. 
Gráfico 4.

Reclusos portugueses e não nacionais condenados por "grupos de crime"*, em 2011, percentualmente**

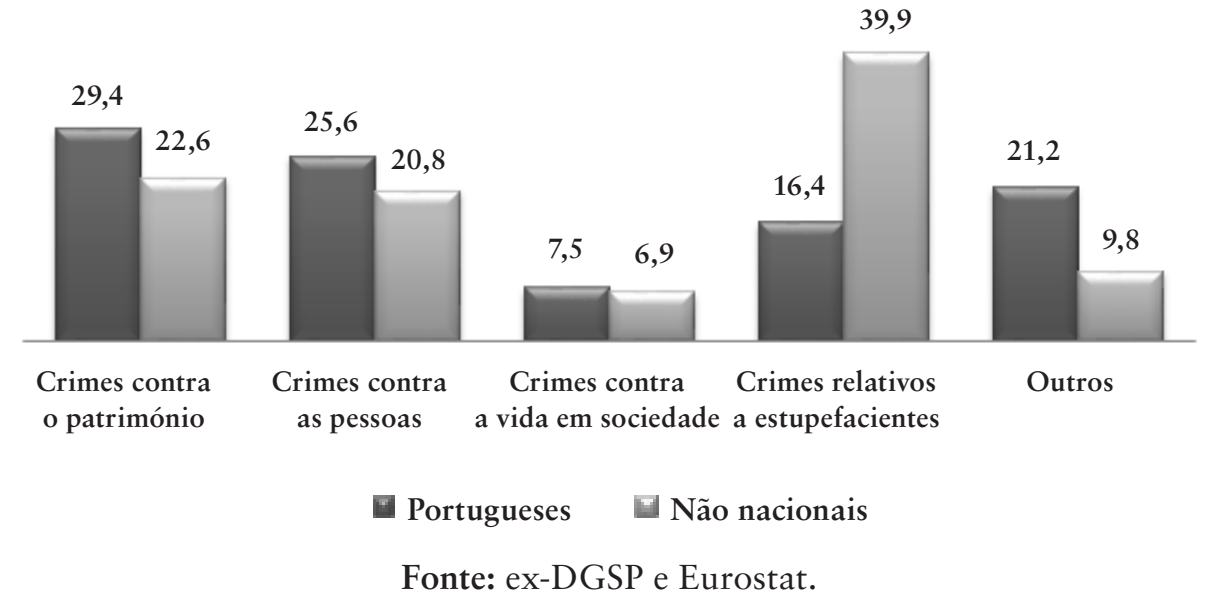

* Estas ponderações foram feitas com base nos dados disponíveis na página da ex-DGSP relativa ao ano de 2011, em que, para os reclusos condenados, constavam 2506 indivíduos por crimes contra o património ( $\mathrm{n}=382$ não nacionais), 2183 por crimes contra as pessoas ( $\mathrm{n}=352$ não nacionais), 635 por crimes contra a vida em sociedade ( $\mathrm{n}=116$ não nacionais), 1399 por crimes relativos a estupefacientes ( $\mathrm{n}=676$ não nacionais) e 1797 por outros crimes ( $\mathrm{n}=165$ não nacionais), para um total de 8520 reclusos portugueses condenados e 1691 reclusos não nacionais. Estes valores incluem os dados de 232 inimputáveis, com medidas de segurança aplicadas, dos quais 95 indivíduos internados em clínicas psiquiátricas prisionais e 137 em hospitais psiquiátricos não prisionais.

* Valor calculado da totalidade de condenações de cada grupo de crime.

É necessário referir que a tipologia criminal revelou alterações no início do século XXI: as condenações por condução de veículo em estado de embriaguez, ofensas à integridade física simples e privilegiada e a emissão de cheques sem provisão deixaram de estar tão presentes nas condenações em Portugal. Passaram a ser mais numerosas, no fim do ano de 2003, "práticas criminosas gravosas como o tráfico de droga $\left.{ }^{22}\right]$ e/ou violentas como o homicídio, o roubo ou o sequestro" (Seabra e Santos, 2006: 56). Constatámos ainda que as nacionalidades dos reclusos não nacionais condenados correspondem, grosso modo, às mesmas que representam o maior número de residentes em Portugal ${ }^{23}$ (cabo-verdianos, brasileiros, guineenses, angolanos, entre outros).

${ }^{22}$ Fonseca aponta para uma predominância dos crimes relativos a estupefacientes para reclusos não nacionais, uma vez que "mais de metade dos estrangeiros reclusos estava condenada por crimes relativos a estupefacientes, uma proporção muito superior à verificada no grupo dos reclusos nacionais" (Fonseca, 2010: 107).

${ }^{23}$ Reclusos condenados não nacionais, em 2011, por nacionalidade: cabo-verdianos, $\mathrm{n}=645$; brasileiros, $\mathrm{n}=258$; guineenses, $\mathrm{n}=196$; angolanos, $\mathrm{n}=179$; espanhóis, $\mathrm{n}=112$; ucranianos, $\mathrm{n}=54$. 
Da análise do Gráfico 4 destacamos a sobrerrepresentação dos crimes relativos a estupefacientes na análise das condenações de reclusos não nacionais em relação às condenações de reclusos portugueses. Quanto aos restantes grupos de crimes, incluindo os crimes violentos, todos eles apresentam uma representação maior no grupo dos condenados portugueses do que no grupo dos não nacionais. No que respeita à média da pena em meses para o total dos condenados não nacionais, verificámos ter havido movimentos oscilantes, mas que, na generalidade, indicavam penas mais altas para reclusos não nacionais. No entanto, na senda do que Fonseca (2010) já havia também concluído ${ }^{24}$, é necessário cruzar mais dados para que se possa apreender mais informação sobre este assunto.

\section{Síntese conclusiva - Imigração e crime: entre a punição $\mathrm{e} a$ inexistência de criminalidade violenta específica}

Os estudos que começaram a debruçar-se sobre a questão da inter-relação entre imigração e crime, nomeadamente os mais recentes estudos norte-americanos e investigações levadas a cabo na Europa, vieram demonstrar que, no que concerne ao crime violento, a entrada de novos imigrantes nos países de destino contribuiu para uma descida do registo de crimes violentos e, quando tal não é totalmente comprovado, apenas os crimes contra a propriedade, nomeadamente o roubo, têm uma expressividade numérica, embora sem significado estatístico.

Em Portugal, os estudos sobre imigração e crime são recentes, havendo uma série de publicações e investigações que se centraram em áreas de fronteira com este tema, nomeadamente os bairros, a vulnerabilidade, a pobreza, o racismo, a discriminação, as prisões, entre outros. As conclusões destes estudos convergem em três ideias principais: 1) não há relação direta entre o aumento do número de imigrantes e o do número de registos por crimes violentos; 2) há uma sobrerrepresentação de indivíduos não nacionais nas prisões; 3) os imigrantes não correspondem à totalidade dos indivíduos não nacionais (havendo os euromigrantes - cidadãos oriundos de um país da UE que decidem estabelecer as suas vidas noutro país da UE -, por exemplo, a considerar e diferenciar), estando os primeiros, pela sua condição, sujeitos a uma maior vulnerabilidade do que os outros, o que os poderá expor a situações mais complexas no que concerne à entrada no mundo do crime. Também se constatou uma alteração significativa na forma como o próprio Estado os tolera, sobretudo se em

24 "Os arguidos estrangeiros registam, no caso de crime de roubo e do crime de tráfico de estupefacientes, menor proporção de penas dos escalões temporais mais baixos e, em regra, maior proporção nos escalões mais elevados. Em ambos os casos, as penas de duração superior a 3 anos, em termos agregados, registam uma proporção mais elevada em cerca de $10 \%$ no grupo de condenados estrangeiros" (Fonseca, 2010: 95). 
situação de irregularidade nos países de destino. Esta situação esteve na base da criminalização da situação de irregularidade em alguns países e do aumento da severidade com que estes indivíduos podem vir a ser julgados (sendo usada a irregularidade para aplicação de prisão preventiva, por exemplo, cfr. al. e), n. ${ }^{\circ}$, art. 202. ${ }^{\circ}$ do Código de Processo Penal), sobretudo se estiverem em causa crimes violentos.

Verifica-se que as nacionalidades dos reclusos condenados (por crimes violentos e não violentos) em Portugal são normalmente as mesmas que têm um maior número de residentes estrangeiros (cf. Seabra e Santos, 2006: 21; Guia, 2008, 2010; Fonseca, 2010: 104), o que nos permite reforçar a conclusão da inexistência de um fenómeno criminal específico relacionado com os imigrantes. É-se criminoso seja onde for e não é a ligação à nacionalidade uma variável direta com o mundo do crime, quer em crimes violentos, quer nos outros que não envolvam violência.

\section{Referências bibliográficas}

ALBRECHT, H. (1997), "Ethnic minorities, crime and criminal justice in Germany", in Tonry, Michael (ed.), Ethnicity, Crime, and Immigration. Comparative and cross-national perspectives. Chicago: The University of Chicago Press, 31-99.

ALMEIDA, M. R. C.; ALÃO, A. P. (1995), Inquérito de Vitimação 1994. Lisboa: Gabinete de Estudos e Planeamento do Ministério da Justiça.

BAGANHA, M. I.; PEREIRA, P.; GÓIS, P. (2005), "International migration from and to Portugal: What do we know and where are we going?", in Zimmermann, Klaus (ed.), European Migration: What do We Know?. Oxford: Oxford University Press, http://www.ces.uc.pt/ myces/UserFiles/livros/721_Maria\%20I.\%20Baganha\%2C\%20Pedro\%20Gois\%2C\%20 and $\% 20$ Pedro\%20T.\%20Pereira\%20\%282006\%29.pdf [3 de fevereiro de 2015].

BARRA DA COSTA, J. (2013), Perfis Psicocriminais. Do Estripador de Lisboa ao Profiler. Lisboa: Pactor.

BITTAR, E. (2006), “Cosmopolitismo e direitos humanos”, Depoimentos - Revista de Direito das Faculdades de Vitória. 10: 11-26.

DAHLBERG, L.; KRUG, E. (2007), "Violência: um problema global de saúde pública”, Ciência e Saúde Coletiva. 11: 1163-1178.

FONSECA, G. (2010), Percursos Estrangeiros no Sistema de Justiça Penal. Lisboa: Observatório da Imigração - ACIDI.

GOMES, S. (2014), Caminhos para a Prisão. Uma análise do fenómeno da criminalidade associada a grupos estrangeiros e étnicos em Portugal. Ribeirão: Edições Húmus.

GUIA, M. J. (2008), Imigração e Criminalidade - Caleidoscópio de imigrantes reclusos. Coimbra: Almedina.

GUIA, M. J. (2010a), Imigração e Criminalidade Violenta: Mosaico da reclusão em Portugal. Lisboa: SEF/INCM.

GUIA, M.J. (2010b) “Imigração e Crime Violento: Verdades e Mitos” in I Congresso Nacional de Segurança e Defesa. Lisboa, Portugal 24-25 de junho de 2010. http://icnsd.afceaportugal.pt/conteudo/congresso/ICNSD_3F_texto_pdf_maria_joao_guia.pdf [25 de agosto de 2014].

GUIA, M.J. (2010c) “Imigrantes e Criminalidade violenta: que relação?” O Cabo dos Trabalhos: Revista Eletrónica dos Programas de Mestrado e Doutoramento do CES/FEUC/FLUC. 5. 
GUIA, M. J. (2014) "Quatro em Linha - um jogo de exclusão: Imigração, Nacionalidade, Cidadania e Crime Violento" in Matos, Raquel (ed.), Género, nacionalidade e reclusão. Olhares cruzados sobre migrações e reclusão feminina em Portugal. Universidade Católica do Porto.

GUIA, M. J. (2015), Imigração, 'Crimigração' e Crime Violento. Os reclusos condenados e as representações sobre imigração e crime. Tese de Doutoramento da Universidade de Coimbra.

IRWIN, J.; AUSTIN, J. (1997), It's About Time: America's Imprisonment Binge. California: Wadsworth.

MALHEIROS, J. (ed.) (2007), Espaços e Expressões de Conflito e Tensão entre Autóctones. Minorias migrantes e não migrantes na área metropolitana de Lisboa. Lisboa: ACIME.

OMS (2002), World Report on Violence and Health. Edited by Etienne G. Krug, Linda L. Dahlberg, James A. Mercy, Anthony B. Zwi and Rafael Lozano. Genebra: WHO Geneva.

PEIXOTO, J. (2004), "País de emigração ou país de imigração? Mudança e continuidade no regime migratório em Portugal”, SOCIUS Working Papers n. ${ }^{\circ}$ 2/2004. Pp. 2-26.

RUMBAUT, R.; EWING, W. (2007), The Myth of Immigrant Criminality and the Paradox of Assimilation. Washington DC: American Immigration Law Foundation.

SAMPSON, R. (2008), "Rethinking immigration and crime", Contexts. 7: 28-33.

SEABRA, H.; SANTOS, T. (2006), Reclusos Estrangeiros em Portugal - Esteios de uma problematização. Lisboa: ACIME.

SOUSA SANTOS, B. (2009), "La globalización, los estados-nación y el campo jurídico: de la diáspora jurídica a la ecúmene jurídica?”, in Sousa Santos, Boaventura (ed.) Sociología Jurídica Crítica. Para un nuevo sentido común en el derecho. Madrid: Trotta: 321-409.

STOWELL, J. (2007), Immigration and Crime: The effects of immigration on criminal behavior. New York: LFB Scholarly Publishing LLC.

WADSWORTH, T. (2010), "Is immigration responsible for the crime drop? An assessment of the influence of immigration on changes in violent crime between 1990 and 2000", Social Science Quarterly. 91(2): 531. 